УДК 616.89-008.441.13:616.8-008.64:616.008-61:616.039.1:615.214.32

Для цитирования: Розин А.И., Рощина О.В., Пешковская А.Г., Белокрылов И.И. Коморбидные сочетания алкогольной зависимости и депрессивных расстройств. Сибирский вестник психиатрии и наркологии. $2018 ; 4$ (101): $40-45$. https://doi.org/10.26617/1810-3111-2018-4(101)-40-45

\title{
Коморбидные сочетания алкогольной зависимости и депрессивных расстройств
}

\section{Розин А.И., Рощина О.В., Пешковская А.Г., Белокрылов И.И.}

Научно-исследовательский институт психического здоровья, Томский национальный исследовательский медицинский центр Российской академии наук (НИИ психического здоровья Томский НИМЦ)

Россия, 634014, Томск, ул. Алеутская, 4

\section{PEЗЮME}

Цель - выявление частоты встречаемости, описание нозологической структуры и клинической типологии депрессивных расстройств у пациентов с алкогольной зависимостью, оценка эффективности комплексной антидепрессивной терапии с использованием психометрических шкал. Материалы и методы: в исследование было включено 110 мужчин с верифицированным диагнозом: Психическое и поведенческое расстройство в связи с употреблением алкоголя. Синдром зависимости (F10.2). Применялись клинико-психопатологический, клинико-динамический, психометрический, клиникокатамнестический, статистический методы исследования. Результаты: частота встречаемости депрессивных расстройств среди пациентов с алкогольной зависимостью составила 32,7\%. Наиболее часто встречается коморбидное сочетание алкоголизма с дистимией, депрессиями легкой и средней степени тяжести. Алкогольная зависимость нередко является причиной развития и видоизменяет проявления депрессии, так же как и депрессия оказывает существенное влияние на характер течения аддиктивной патологии. В статье показана эффективность комплексной персонализированной терапии депрессивных расстройств при алкогольной зависимости. пия.

Ключевые слова: алкогольная зависимость, депрессивные расстройства, антидепрессанты, антикрейвинговая тера-

\section{ВВЕДЕНИЕ}

Внимание специалистов в области наркологии привлекают различные аспекты клиники зависимости, в частности облигатно сопровождающие её аффективные расстройства [1].

В рамках психиатрической службы до $35 \%$ мужчин, наблюдаемых по поводу депрессивных расстройств, имеют в той или иной степени явления алкоголизации, соответствующие нозологическим критериям. С другой стороны, у 25-59\% наркологических больных в процессе противоалкогольной терапии отмечаются депрессивные состояния [2, 3].

Не вызывает сомнений, что, с одной стороны, зависимость от психоактивных веществ неблагоприятно сказывается на течении аффективных расстройств, а с другой - наличие аффективной патологии служит фактором, ускоряющим формирование и отягощающим течение зависимости от психоактивных веществ. Подобные сочетанные формы зависимости отличаются в целом худшим прогнозом течения и результатами психофармакологического лечения, высоким риском суицидов [4]. При этом аффективные расстройства длительное время часто остаются не диагностированными в виду полиморфизма симптоматики, маскированности депрессивных симптомов [5].

Так называемые вторичные депрессии являются следствием хронической алкогольной интоксикации и встречаются у 40-60\% больных хроническим алкоголизмом. Отмечено, что наличие злоупотребления алкоголем в анамнезе более чем в 4 раза повышает вероятность развития у больного депрессивного эпизода [6].
Аффективная патология при алкоголизме тесно связана с проявлениями патологического влечения и требует дифференцированного подбора адекватной терапии. Коррекция аффективных расстройств является одним из важнейших компонентов противорецидивной терапии алкоголизма [14].

При изучении патогенеза алкогольной зависимости обнаружена общность основных нейрохимических механизмов депрессии и патологического влечения к алкоголю и прямая зависимость актуализации и регресса крейвинга с углублением или ослаблением депрессивной симптоматики [7]. Установлено, что этанол нарушает обмен моноаминов в ЦНС, и в первую очередь обмен дофамина - нейромедиатора, участвующего в регуляции эмоциональной сферы через так называемую систему положительного подкрепления [8]. Серотонинергической дисфункцией (врожденной или приобретенной), а также связанными с ней коморбидными психическими расстройствами - депрессией и другими психопатологическими состояниями - обосновывается использование антидепрессантов в лечении алкоголизма [9]. Выявление роли нарушений катехоламинов и серотонина в формировании патологического влечения к алкоголю открывает путь к применению патогенетически обоснованной терапии алкоголизма [10].

\section{ЦЕЛЬ ИССЛЕДОВАНИЯ}

Выявление частоты встречаемости, описание нозологической структуры и клинической типологии депрессивных расстройств у пациентов с алкогольной зависимостью, а также оценка эффективности комплексной антидепрессивной терапии с использованием психометрических шкал. 


\section{МАТЕРИАЛ И МЕТОДЫ}

Объектом исследования являлись пациенты с верифицированным диагнозом алкогольной зависимости (Психические расстройства и расстройства поведения, связанные с употреблением алкоголя. Синдром зависимости. F10.2 по МКБ-10), прошедшие лечение в отделении аддиктивных состояний НИИ психического здоровья ТНИМЦ. Все пациенты были мужского пола в возрасте от

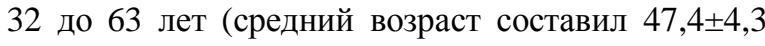
года).

Обязательным условием включения больных в исследование было их информированное согласие, подтвержденное решением Этического комитета, в соответствии с Законом РФ «О психиатрической помощи и гарантиях прав граждан при ее оказании» (в ред. Ф3 от 10.01.2003 № 15-Ф3) и ст. 32 «Основ законодательства РФ об охране здоровья граждан» (в ред. Ф3 от 01.12.2004 № 151-Ф3).

Проводилось сплошное обследование больных с алкогольной зависимостью, госпитализированных в отделение аддиктивных состояний, с использованием Госпитальной шкалы тревоги и депрессии (HADS). Пациенты с клиническим и субклиническим уровнями тревоги и депрессии по HADS более 8 баллов были проконсультированы психиатром прицельно для выявления клинически оформленного депрессивного расстройства. Больные, набравшие более 8 баллов хотя бы по одной из подшкал HADS, заполняли ряд дополнительных опросников: самоопросник депрессии Бека (BDI), шкалу самооценки социальной адаптации
(SASS). Диагноз аффективных расстройств устанавливался по результатам клинического интервью в соответствии с диагностическими критериями МКБ-10. Для динамической оценки психического состояния использовались психометрические шкалы (шкала депрессии МонтгомериAсберга (MADRS), шкала глобальной клинической оценки (CGI), обсессивно-компульсивная шкала оценки влечения к алкоголю, визуальная аналоговая шкала влечения к алкоголю).

Статистическую обработку данных проводили с помощью пакета стандартных прикладных программ Statistica for Windows (V.6.0). Применялся $\mathrm{U}$-критерий Манна-Уитни для сравнения независимых выборок. Количественные данные представлены в виде $\mathrm{M} \pm \mathrm{SD}$, где $\mathrm{M}$ - среднее арифметическое, SD - стандартное отклонение (соответствие нормальности распределения проводилось с применением критерия Шапиро-Уилка); в случае распределения отличного от нормального количественные данные представлены в виде медианы, нижнего и верхнего квартилей.

\section{РЕЗУЛЬТАТЫ И ОБСУЖДЕНИЕ}

В исследование было включено 110 пациентов. Частота депрессивных расстройств среди больных с алкогольной завивисимостью наркологического стационара составила $32,7 \%$. В результате проведенного психодиагностического и клиникопсихопатологического исследования у 18 из 55 пациентов были диагностированы депрессивные расстройства, относящиеся к различным нозологическим рубрикам (табл. 1).

Т а б л и ц а 1

Нозологическая структура депрессивных расстройств у пациентов с алкогольной зависимостью

\begin{tabular}{|c|l|c|c|}
\hline \multicolumn{2}{|c|}{ Диагноз психического расстройства по МКБ-10 } & \multicolumn{2}{c|}{ Количество пациентов } \\
\cline { 3 - 5 } & абс. & $\%$ \\
\hline F32.0 & Депрессивный эпизод легкой степени & 4 & 11,1 \\
\hline F32.1 & Депрессивный эпизод умеренной степени & 6 & 16,7 \\
\hline F34.1 & Дистимия & 12 & 33,3 \\
\hline F33.1 & Рекуррентное депрессивное расстройство, текущий эпизод умеренной степени & 4 & 11,1 \\
\hline F43.22 & Смешанная тревожно-депрессивная реакция & 10 & 27,8 \\
\hline \multicolumn{2}{|c|}{ Всего } & 36 & 100,0 \\
\hline
\end{tabular}

В диагностическом плане среди всех больных алкоголизмом с депрессией в 72,2\% случаев выявлялись аффективные расстройства настроения (F3). Наиболее частым диагнозом было хроническое расстройство настроения - дистимия, зарегистрированная у 33,3\% больных, что указывало на преимущественно длительный характер существования депрессивных расстройств. В большинстве случаев наблюдались депрессии легкой и умеренной степени тяжести.

Учитывая анамнестические сведения и в соответствии с ретроспективным анализом объективной информации по материалам медицинской документации, было установлено, что в 55,5\% случаев депрессивное расстройство предшествовало выявлению алкогольной зависимости, тогда как в $44,5 \%$ случаев депрессия была выявлена на фоне ранее развившегося алкоголизма. Депрессия и алкоголизм находятся в реципрокных отношениях, каждое из которых утяжеляет течение другого заболевания. Алкогольная зависимость часто является причиной развития и видоизменяет проявления депрессии, так же как и депрессия оказывает существенное влияние на характер течения аддиктивной патологии.

В соответствии с исследованиями отечественных наркологов [10], посвященными изучению типологии аффективных расстройств при алкогольной зависимости, были выделены первичные и вторичные депрессии. Первичные депрессии предшествуют развитию алкоголизма. Развитие их связано с первичной психической патологией, а алкоголизм уже формируется на их фоне вторично. 
Таким образом, речь идет о наличии у больного сразу двух заболеваний. Как правило, это эндогенная депрессия в рамках аффективных расстройств настроения (рубрика F3 по МКБ-10). Мотивом пьянства для таких больных является избавление от тягостного состояния, тоски, тревоги, заторможенности, одиночества и опустошенности [17]. Такие пациенты прибегают к приему алкоголя в большей степени с целью избавления от дискомфорта, а не для достижения эйфории. В синдромологической структуре первичных депрессивных расстройств присутствовали синдромы: депрессивный $(38,9 \%)$, тревожно-депрессивный (33,3\%), дисфорический $(27,8 \%)$.

Депрессивный синдром характеризуется пониженным настроением, падением работоспособности, снижением интереса к окружающему и своим проблемам, ухудшением сна и снижением аппетита. Колебания настроения носят как циклоидный характер («хуже по утрам», отсутствие облегчения и отдыха после сна), так и протекают по астеническому типу (ухудшение настроения и падение тонуса к вечеру). В эту симптоматику вкрапляются эпизоды тревоги с чувством внутреннего напряжения и ожидания чего-то неприятного.

При тревожно-депрессивном синдроме эти расстройства (внутреннее беспокойство, напряжение, ожидание неприятностей, невозможность отключиться от мыслей о плохом исходе любых актуальных ситуаций) носят постоянный характер.

Дисфорической синдром определяется сочетанием пониженного настроения с раздражительностью, а в ряде случаев со злобностью, затрудняющими контакты больного с окружающим, провоцирующими постоянные конфликтные ситуации вокруг больного дома и в служебной обстановке.

Вторичные депрессии $(44,5 \%)$ отличались полиморфизмом и типовой неоднородностью аффекта, характеризовались малой дифференцированностью, полиморфностью, преобладанием тревожной и дисфорической симптоматики. Для аффективных нарушений, развившихся при алкогольной зависимости, характерными были атипичность, незавершенность синдромальной картины, нестойкость, изменчивость и резкие колебания глубины аффективных нарушений. Практически отсутствовали признаки витальности и суточные колебания состояния, не свойственна классическая депрессивная триада (сниженное настроение, интеллектуальная и двигательная заторможенность).

По шкале HADS средний общий балл депрессии составил 12 (9-16), по субшкале тревоги - 11 (9-13), соответствующие субклинически и клинически выраженным тревоге и депрессии. По шкале самооценки депрессии Бека средний балл составлял 23 (20-25), соответствуя клинически выраженной депрессии (более 19) и депрессии, требующей лекарственного лечения (более 24 баллов), что отражало субъективную оценку пациентами тяжести их эмоциональных нарушений.
Далее обсуждаются данные, полученные по объективным психометрическим шкалам. Средний суммарный общий балл по MADRS составил 22 (20-26), т.е. легкая и умеренная степень депрессии; по шкале тревоги Гамильтона - 12 (11-14) баллов - легкая степень выраженности тревоги. По шкале глобального клинического впечатления в 55,5\% случаев степень тяжести расстройств оценивалась как умеренная, у трети больных $(33,3 \%)$ были зафиксированы значительно выраженные расстройства, у 11,1\% - слабо выраженные психические нарушения. Более половины больных $(55,5 \%)$ адекватно оценивали свое психическое состояние и признавали наличие депрессивного расстройства, принимали необходимость лечения антидепрессантами.

Проблема выявления и распознавания депрессии врачами в наркологической службе представляет собой актуальную задачу в медицинской практике. Имеющиеся затруднения могут быть объяснены отсутствием достаточного количества времени в связи с большим потоком больных, маскированным характером депрессии. Актуальность и важность решения этих вопросов обусловлены тем, что большинство наркологических пациентов напрямую не предъявляют жалоб депрессивного спектра, имеют алекситимические черты, а клиническая картина депрессии зачастую имеет атипичность, незавершенность синдромальной картины.

Применение у больных хроническим алкоголизмом антидепрессантов трициклической структуры и ингибиторов МАО осложнено в связи с их множественными побочными эффектами и нежелательными интеракциями. Критериям малой токсичности, сохранения работоспособности больного наиболее соответствуют современные антидепрессанты группы селективных ингибиторов обратного захвата серотонина. Однако в последние годы в литературе накапливаются данные о том, что антидепрессанты из группы СИОЗС недостаточно эффективно влияют на ангедонию - один из ключевых симптомов депрессии и аддиктивных расстройств [12]. Современные антидепрессанты (агомелатин, вортиоксетин), обладающие широким спектром действия, воздействующие, в том числе, на хронобиологические и дофаминергические механизмы, играющие главную роль в функционировании системы вознаграждения, представляются наиболее перспективными в терапии пациентов с депрессивными расстройствами и алкогольной зависимостью [13].

В нашем исследовании пациенты с депрессивными расстройствами и алкогольной зависимостью получали сертралин 100 мг, агомелатин 50 мг, вортиоксетин 20 мг. Следует отметить, что при терапии агомелатином во всех случаях наблюдения требовалось повышение дозы до максимальной для достижения оптимального терапевтического ответа. 
На фоне применения сертралина у 3 из 4 пациентов отмечались сексуальные дисфункции, вероятно связанные с приемом антидепрессанта, чего не было при использовании агомелатина и вортиоксетина [16].

В ходе психотерапевтической работы использовались в основном рациональный и когнитивноповеденческий подходы. Пациент изначально был информирован о тактике и длительности предстоящего лечения. С пациентом обсуждались возможные достижимые результаты лечения депрессивных расстройств. В работе с депрессивными больными делался акцент на смещения фокуса их внимания вовне, ухода от зацикливания на своих собственных переживаниях. Осуществлялась по- мощь пациентам в формировании стратегии позитивного мышления и восприятия окружающего. Центральным звеном в работе с пациентами являлось изучение их мотиваций, поиск приоритетных и актуальных целей в более широком понимании, смысла жизни, четкое формулирование стремлений на достижение поставленных целей. Описанные направления психотерапевтической работы осуществлялись с учетом личностных особенностей пациентов, индивидуального восприятия наличия основной аддиктивной патологии $[15,18]$.

Эффективность комплексного психофармакологического и психотерапевтического воздействия оценивалась с использованием психометрических шкал в начале терапии и через 4 недели лечения.

Т а б л и ц а 2

Оценка эффективности терапии при депрессивных расстройствах у пациентов с алкогольной зависимостью

\begin{tabular}{|l|c|c|}
\hline \multicolumn{1}{|c|}{ Общий суммарный балл по психометрическим школам } & До терапии & После терапии \\
\hline Обсессивно-компульсивная шкала патологического влечения к алкоголю & $18(16-19)$ & $5(3-6)$ \\
\hline Визуально-аналоговая шкала влечения к алкоголю & $84(73-90)$ & $9(7-12)$ \\
\hline Госпитальная шкала тревоги и депрессии (депрессия) & $12(9-16)$ & $3(2-5)$ \\
\hline Госпитальная шкала тревоги и депрессии (тревога) & $11(9-13)$ & $5(4-6)$ \\
\hline Шкала депрессии Бека & $23(20-25)$ & $9(7-10)$ \\
\hline Шкала тревоги Гамильтона & $12(11-14)$ & $6(5-8)$ \\
\hline Шкала депрессии Монтгомери-Асберга & $22(20-26)$ & $4(3-5)$ \\
\hline Шкала самоценки социальной адаптации & $28(23-31)$ & $39(34-42)$ \\
\hline
\end{tabular}

П р и м е ч а н и е. Достоверность различий $-\mathrm{p}<0,05$ критерий Манна-Уитни.

Приведенные в таблице 2 данные свидетельствуют о том, что у пациентов на начальном этапе отмечалось достаточно высоко интенсивное патологическое влечение к алкоголю, зафиксированное как по Обсессивно-компульсивной шкале, так и по Визуально-аналоговой шкале, со значительной редукцией этих показателей после прохождения лечебно-реабилитационных программ.

В структуре аффективных нарушений у пациентов с алкогольной зависимостью тревожная симптоматика была более выражена, чем депрессивная (по данным субъективного опросника HADS), однако в динамике тревога редуцировалась значительнее. По объективной шкале депрессии Монтгомери-Асберга цифровые значения до лечения соответствовали уровню депрессии легкой и умеренной степени. В динамике выявлена значимая редукция депрессивной симптоматики.

Клиническая эффективность проводимого лечения по шкале глобального клинического впечатления в 94,4\% случаев оценивалась как значительная. В ходе терапии с применением мелатонинергического антидепрессанта с хронобиологическим действием агомелатина у пациентов значительно редуцировались диссомнические расстройства, ночной сон нормализовался уже на первой неделе терапии, облегчился процесс засыпания, углубился сон, уменьшились ночные пробуждения. Алкогольная тематика сновидений как компонент патологического влечения к алкоголю редуцировалась к окончанию второй недели терапии у 2/3 пациентов, принимавших агомелатин.
Достигнутые в результате лечения регресс патологического влечения к алкоголю, улучшение психоэмоционального состояния пациентов, значительная редукция симптоматики депрессии, зафиксированные как по субъективным, так и по объективным психометрическим шкалам, демонстрируют эффективность данного метода при лечении пациентов с алкогольной зависимостью в сочетании с депрессивными расстройствами.

\section{ЗАКЛЮЧЕНИЕ}

Преимущество представленного алгоритма диагностики и терапии алкоголизма, коморбидного с депрессивными расстройствами, заключается в том, что его использование позволяет повысить терапевтическую эффективность за счет своевременного выявления коморбидного сочетания аффективных расстройств и аддиктивной патологии. Психофармакотерапия с использованием антидепрессантов последних генераций позволяет более эффективно воздействовать на крейвинг - ядро психопатологической симптоматики у пациентов с алкогольной зависимостью. Применение этого алгоритма открывает новые возможности повышения эффективности терапии алкогольной зависимости. Лечебно-диагностическая работа, опирающаяся на приоритетную своевременную диагностику коморбидности в психиатрии и наркологии, а также использование персонализированного психофармако-психотерапевтического лечебнореабилитационного комплекса расширяет арсенал терапевтических возможностей в наркологической практике. 
Тем не менее имеются ограничения, так как формат проведенного исследования не предполагал введение группы сравнения, что затрудняет доказательство эффективности терапии.

\section{КОНФЛИКТ ИНТЕРЕСОВ}

Авторы заявляют об отсутствии конфликта интересов в связи с публикацией данной статьи.

\section{ИСТОЧНИК ФИНАНСИРОВАНИЯ}

Исследование выполнено при финансовой поддержке РФФИ в рамках научного проекта № 18313-00147 и по программе поисковых научных исследований НИИ психического здоровья «Разработка методов персонализированной терапии у больных аддиктивными расстройствами». Шифр темы 0550-2016-0401. Номер госрегистрации AAAA-A16-116042610053-7.

\section{СООТВЕТСТВИЕ ПРИНЦИПАМ ЭТИКИ}

Работа соответствует этическим стандартам Хельсинкской декларации ВМА. Исследование одобрено локальным этическим комитетом НИИ психического здоровья Томского национального исследовательского медицинского центра РАН.

\section{ЛИТЕРАТУРА}

1. Baker A.L., Thornton L.K., Hiles S., Hides L., Lubman D.I. Psychological interventions for alcohol misuse among people with co-occurring depression or anxiety disorders: A systematic review. Journal of Affective Disorders. 2012; 139 (3): 217-229.

2. Бохан Н.А., Семке В.Я. Коморбидность в наркологии. Томск: Издательство Томского университета, 2009: 510.

3. Бохан Н.А., Мандель А.И., Артемьев И.А., Ветлугина Т.П., Солонский А.В., Прокопьева В.Д., Иванова С.А., Невидимова Т.И. Эпидемиология, клинико-патобиологические закономерности и профилактика психических и поведенческих расстройств в результате злоупотребления психоактивными веществами (региональный аспект). Сибирский вестник психиатрии и наркологии. 2006; 3 (42): 25-32.

4. Сыропятов О. Г., Дзеружинская Н. А. Патогенез и биологическое лечение алкоголизма: Пособие для врачей. Киев: УВМА, 2000: 46

5. Бохан Н.А., Мандель А.И., Пешковская А.Г., Бадыргы И.О., Асланбекова Н.В. Этнотерриторальная гетерогенность формирования алкогольной зависимости у коренного населения Сибири. Журнал неврологии и психиатрии им. С.С. Корсакова. 2013; 6. Вып. 2. Алкоголизм: 9-14.
6. Кинкулькина М.А., Иванец Н.Н. Депрессии при шизофрении и алкоголизме. Клиника и лечение. М.: ИД Медпрактика-М, 2009: 216.

7. Менделевич В.Д. Синдром зависимости: терапия, основанная на доказательствах. Наркология. 2014; 8: 94-103.

8. Чекман И.С. Фармакология. Винница: Издательство «Новая книга», 2013: 160-170

9. Смулевич А.Б., Дубницкая Э.Б., Тхостов А.Ш. и др. / под ред. А.Б. Смулевича. Депрессии и коморбидные расстройства. М., 1997: 416.

10. Обухов С.Г. Курс лекций по психиатрии. Пособие для студентов лечебного факультета медицинских ВУЗов. Гродно: ГрГМУ, 2006:137

11. Иванец Н.Н. Граница и классификация наркологических заболеваний. Лекции по наркологии / под ред. Н.Н. Иванца. М.: Нолидж, 2000: 297.

12. Treadway M.T., Zald D.H. Reconsidering anhedonia in depression: lessons from translational neuroscience. Neurosci Biobehav Rev. 2011; 35: 537-55.

13. Brady K.T., Verduin M.L., Tolliver B.K. Treatment of patients comorbid for addiction and other psychiatric disorders. Curr Psychiatry Rep. 2007; October, 9 (5): 374-380.

14. Счастный Е.Д., Семке А.В., Размазова Л.Д., Симуткин Г.Г., Лебедева Е.В., Невидимова Т.И., Розин А.И., Чернышева К.Г., Шепенев А.М., Шахурова Н.И. Биологические и клинико-социальные механизмы развития аффективных расстройств. Сибирский вестник психиатрии и наркологии. 2013; 5 (80): 18-27.

15. Куприянова И.Е., Счастный Е.Д. Актуальные вопросы психиатрии и наркологии. Юбилейная научная конференция, посвященная 35-летию Научно-исследовательского института психического здоровья и 125-летию кафедры психиатрии, наркологии и психотерапии Сибирского государственного медицинского университета. Журнал неврологии и психиатрии им. С.С. Корсакова. 2017; 117 (4): 121-122.

16. Счастный Е.Д, Симуткин Г.Г, Лебедева Е.В, Яковлева А.Л., Лосенков И.С, Левчук Л.А, Сергиенко Т.Н, Муслимова Э.Ф, Репин Н.А., Нонка Т.Г, Иванова С.А. Клиникобиологические факторы полиморфизма и эффективности терапии аффективных расстройств. Сибирский вестник психиатрии и наркологии. 2016; 4 (93): 26-32.

17. Бохан Н.А., Семке В.Я., Мандель А.И. Персонологический анализ в контексте систематики аддиктивных состояний. Наркология. 2006; 1: 60-65.

18. Пешковская А.Г. Этнокультуральный диспаритет когнитивных нарушений при алкоголизме. Неврологический вестник им. В.М. Бехтерева. 2014; 46 (3): 97-98.

Поступила в редакцию 2.07.2018 Утверждена к печати 6.11.2018

Розин Александр Иосифович, к.м.н., врач-психиатр отделения аддиктивных состояний.

Рощина Ольга Вячеславовна, младший научный сотрудник отделения аффективных состояний.

Пешковская Анастасия Григорьевна, младший научный сотрудник отделения аддиктивных состояний.

Белокрылов Илья Игоревич, младший научный сотрудник отделения аддиктивных состояний.

УДК 616.89-008.441.13:616.8-008.64:616.008-61:616.039.1:615.214.32

For citation: Rozin A.I., Roshchina O.V., Peshkovskaya A.G., Belokrylov I.I. Comorbid combinations of alcohol dependence and depressive disorders. Siberian Herald of Psychiatry and Addiction Psychiatry. 2018; 4 (101): 40-45. https://doi.org/10.26617/1810-3111-2018-4(101)-40-45

\section{Comorbid combinations of alcohol dependence and depressive disorders}

\section{Rozin A.I., Roshchina O.V., Peshkovskaya A.G., Belokrylov I.I.}

Mental Health Research Institute, Tomsk National Research Medical Center, Russian Academy of Sciences Aleutskaya Street 4, 634014, Tomsk, Russian Federation

\section{ABSTRACT}


Objective: to identify the frequency of occurrence, to describe the nosological structure and the clinical typology of depressive disorders in the case of comorbidity with alcohol dependence, to estimate the effectiveness of complex antidepressant therapy using psychometric scales. Material: the study included 110 men with a verified diagnosis of mental and behavioral disorders due to alcohol use. Dependence syndrome (F10.2 according to ICD-10). Methods: clinical-psychopathological, clinical-dynamic, psychometric, clinical-catamnestic, statistical. Results: the incidence of depressive disorders among patients with alcohol dependence was $32.7 \%$. The comorbidity of alcohol use disorder with dysthymia, depression of mild and moderate severity is the most common. Alcohol dependence is often the cause of development and modifies the manifestations of depression, as well as depression has a significant effect on the nature of the course of addictive pathology. The article shows the effectiveness of complex personalized therapy of depressive disorders in alcohol dependence.

\section{Keywords: alcohol dependence, depressive disorders, antidepressants, anticravating therapy.}

\section{REFERENCES}

1. Baker A.L., Thornton L.K., Hiles S., Hides L., Lubman D.I. Psychological interventions for alcohol misuse among people with co-occurring depression or anxiety disorders: A systematic review. Journal of Affective Disorders. 2012; 139 (3): 217-229.

2. Bokhan N.A., Semke V.Ya. Komorbidnost' v narkologii [Comorbidity in narcology]. Tomsk: Izd-vo Tom. un-ta, 2009: 510 (in Russian).

3. Bokhan N.A., Mandel A.I., Artemyev I.A., Vetlugina T.P., Solonsky A.V., Prokopyeva V. D., Ivanova S.A., Nevidimova T.I. Epidemiologiya, kliniko-patobiologicheskie zakonomernost i profilaktika psikhicheskikh i povedencheskikh rasstroystv v rezul'tate zloupotrebleniya psikhoaktivnymi veshchestvami (regional'nyy aspekt) [Epidemiology, pathobiological regulatrities of prevention of mental and behavioral disorders as a result of substabce abuse (regional aspect)]. Sibirskii vestnik psikhiatrii $i$ narkologii - Siberian Herald of Psychiatry and Addiction Psychiatry. 2006; 3 (42): 25-32 (in Russian).

4. Syropyatov O.G., Dzeruzhinskaya N.A. Patogenez i biologicheskoe lechenie alkogolizma: Posobie dlya vrachei [Pathogenesis and biological treatment of alcoholism: manual for doctors]. Kiev: UVMA, 2000: 46 (in Russian).

5. Bokhan N.A., Mandel A.I., Aslanbekova N.V., Peshkovskaya A.G. Etnoterritoral'naya geterogennost' formirovaniya alkogol'noy zavisimosti u korennogo naseleniya Sibiri [Ethnoterritorial heterogeneity of formation of alcohol dependence in the native population of Siberia]. Zhurnal nevrologii i psikhiatrii im. S.S. Korsakova - SS Korsakov Journal of Neurology and Psychiatry. 2013; 6. Issue 2. Alcoholism: 9-14 (in Russian).

6. Kinkul'kina M.A., Ivanets N.N. Depressii pri shizofrenii i alkogolizme. Klinika i lechenie [Depression in schizophrenia and alcoholism. Clinic and treatment. Moscow: Izdlatelsky house of Medpraktika-M, 2009: 216 (in Russian).

7. Mendelevich V.D. Sindrom zavisimosti: terapiya, osnovannaya na dokazatel'stvakh [Dependence syndrome: evidence-based therapy]. Narkologiya - Narcology. 2014; 8: 94-103 (in Russian).

8. Chekman I.S. Farmakologiya [Pharmacology]. Vinnytsia: Publishing house «New book», 2013: 160-170 (in Russian).

9. Smulevich A.B., Dubnitskaya E.B., Tkhostov A.Sh. i dr. / pod red. A.B. Smulevicha. Depressii i komorbidnye rasstroistva [Depression and comorbid disorders] M., 1997. S. 28 - 53 (in Russian).

10. Obukhov S. G. Kurs lektsii po psikhiatrii [Course of lectures on psychiatry]. Grodno, 2006 (in Russian).

11. Ivanets N.N. Granitsa i klassifikatsiya narkologicheskikh zabolevanii. Lektsii po narkologii [Boundary and classification of narcological diseases. Lectures on narcology] / Pod red.
Ivantsa N.N. Moscow: Publishing House Nolidzh, 2000: 60-97 (in Russian).

12. Treadway M.T., Zald D.H. Reconsidering anhedonia in depression: lessons from translational neuroscience. Neurosci Biobehav Rev. 2011; 35: 537-55.

13. Brady K.T., Verduin M.L., Tolliver B.K. Treatment of patients comorbid for addiction and other psychiatric disorders. Curr Psychiatry Rep. 2007; October, 9 (5): 374-380.

14. Schastnyy E.D., Semke A.V., Rakhmazova L.D., Simutkin G.G., Lebedeva E.V., Nevidimova T.I., Rozin A.I., Chernysheva K.G., Shepenev A.M., Shakhurova N.I. Biologicheskie i klinikosotsial'nye mekhanizmy razvitiya affektivnykh rasstroystv [Biological and clinical-social mechanisms of development of affective disorders]. Sibirskiy vestnik psikhiatrii i narkologii-Siberian Herald of Psychiatry and Addiction Psychiatry. 2013; 5 (80): 18-27 (in Russian).

15. Kupriyanova I.E., Schastnyy E.D. Aktual'nye voprosy psikhiatrii i narkologii. Yubileynaya nauchnaya konferentsiya, posvyashchennaya 35-letiyu Nauchno-issledovatel'skogo instituta psikhicheskogo zdorov'ya i 125-letiyu kafedry psikhiatrii, narkologii i psikhoterapii Sibirskogo gosudarstvennogo meditsinskogo universiteta [Relevant issues of psychiatry and addiction psychiatry. Jubilee Scientific Conference devoted to the $35^{\text {th }}$ anniversary of Mental Health Research Institute and the $125^{\text {th }}$ anniversary of the Department of Psychiatry, Narcology and Psychotherapy of Siberian State Medical University]. Zhurnal nevrologii i psikhiatrii im. S.S. Korsakova - SS Korsakov Journal of Neurology and Psychiatry. 2017; 117 (4): 121-122 (in Russian).

16. Schastnyy E.D, Simutkin G.G., Lebedeva E.V, Yakovleva A.L., Losenkov I.S., Levchuk L.A., Sergienko T.N., Muslimova E.F., Repin A.N., Nonka T.G., Ivanova S.A. Kliniko-biologicheskie faktory polimorfizma i effektivnosti terapii affektivnykh rasstroystv [Clinical-biological factors of polymorphism and efficiency of the therapy of affective disorders]. Sibirskiy vestnik psikhiatrii i narkologii - Siberian Herald of Psychiatry and Addiction Psychiatry. 2016; 4 (93): 26-32 (in Russian).

17. Bokhan N.A., Semke V.Ya., Mandel A.I. Personologicheskiy analiz v kontekste sistematiki addiktivnykh sostoyaniy [Personological analysis in the context of systematization of addictive states]. Narkologiya - Narcology. 2006; 1: 60-65 (in Russian).

18. Peshkovskaya A.G. Etnokul'tural'nyy disparitet kognitivnykh narusheniy pri alkogolizme [Ethnocultural disparity of cognitive violations at alcoholism]. Nevrologicheskiy vestnik im. V.M. Bekhtereva - V.M. Bekhterev Neurological Bulletin. 2014; 46 (3): 97-98 (in Russian).

Received Jules 2.2018 Accepted November 6.2018

Rozin Alexander I., PhD, psychiatrist of Addictive States Department, Mental Health Research Institute, Tomsk National Research Medical Center, Russian Academy of Sciences, Tomsk, Russian Federation.

Roshchina Olga V., junior researcher of Affective States Department, Mental Health Research Institute, Tomsk National Research Medical Center, Russian Academy of Sciences, Tomsk, Russian Federation.

Peshkovskaya Anastasia G., junior researcher of Addictive States Department, Mental Health Research Institute, Tomsk National Research Medical Center, Russian Academy of Sciences, Tomsk, Russian Federation.

Belokrylov Ilya I., junior researcher of Addictive States Department, Mental Health Research Institute, Tomsk National Research Medical Center, Russian Academy of Sciences, Tomsk, Russian Federation. 